\title{
Optic disc size and optic nerve damage in normal pressure glaucoma
}

Department of Ophthalmology and Eye Hospital of the Friedrich-AlexanderUniversity, ErlangenNürnberg, Germany J B Jonas

K I Papastathopoulos A Dichtl

Department of Ophthalmology and University Eye Hospital, Zürich, Switzerland

J Stürmer

F Meier-Gibbons

Correspondence to: Dr J Jonas, University Eye Hospital, Schwabachanlage 6 91054 Erlangen, Germany.

Accepted for publication 14 August 1995

Jost B Jonas, Jörg Stürmer, Konstantinos I Papastathopoulos, Frances Meier-Gibbons, Albert Dichtl

\begin{abstract}
Background-Recent reports indicate that eyes with normal pressure glaucoma have larger optic discs than eyes with primary open angle glaucoma or normal eyes. This study was performed to find whether, in normal pressure glaucoma, a large disc is associated with more optic nerve damage than a small disc.

Methods-Colour optic disc photographs of 74 patients with normal pressure glaucoma were assessed morphometrically.

Results-Taking the study group as a whole, the optic disc size decreased significantly $(p=0.04)$ with increasing visual field defect. In an intraindividual bilateral comparison, the side differences in the disc area of the right minus the left eye of the same individual were not significantly correlated with the side differences in the mean visual field defect. Conclusions-The results indicate that the eye with the larger optic disc, when compared with the contralateral eye with the smaller optic nerve head, showed neither a significantly more marked nor less pronounced glaucomatous optic nerve damage. It suggests that for a given patient the degree of glaucomatous optic nerve atrophy was not markedly associated with the optic disc size. The finding that patients with large visual field defects had smaller discs than patients with moderate perimetric loss may indicate that the results of previous cross sectional studies reporting on an unusually large disc size in normal pressure glaucoma may be due partially to selection.

(Br 7 Ophthalmol 1995; 79: 1102-1105)
\end{abstract}

In recent studies on the morphology of the optic nerve head a large optic disc size has been suggested as being a risk factor for a glaucoma. ${ }^{1-4}$ The abnormally large optic nerve head in blacks compared with whites has been thought to be responsible for the increased glaucoma susceptibility in the Afro-American group. ${ }^{1}$ In several studies on the different types of the open angle glaucoma, the optic disc was significantly larger in eyes with normal pressure glaucoma than in eyes with primary open angle glaucoma, glaucoma eyes with pseudoexfoliation, or normal eyes. ${ }^{2-4}$ It was suggested that the large optic disc was one among other factors predisposing to a glaucomatous optic nerve fibre loss even in the presence of a statistically normal intraocular pressure.

It could not be excluded with certainty, however, that the large optic disc size in the normal pressure glaucoma group was due to the selection of patients. Eyes with small optic discs physiologically have small optic cups. ${ }^{5-7}$ In early and medium advanced stages of normal pressure glaucoma, not all of these eyes might be considered to be glaucomatous, since a glaucomatous minicup in a small optic disc with low cup/disc ratios looks pseudonormal. ${ }^{8}$ Visual field defects present in these patients might be attributed to irregularities in the optic media, unspecific ocular or cerebral perfusion problems, or unknown neurological reasons. A perimetric loss might also be detected late because there seems to be no need for a visual field test if the intraocular pressure is normal and the optic disc appears to be unremarkable. This may lead to a preferred selection of eyes with large optic discs in the normal pressure glaucoma group. ${ }^{9}$

The present study was performed to find whether a large disc is associated with more optic nerve damage in normal pressure glaucoma than a small disc, or whether the occurrence of a large optic disc size in normal pressure glaucoma, as found in previous studies, ${ }^{2-4}$ may be due partially to the selection of patients.

\section{Material and methods}

The study consisted of 148 eyes of 74 patients (49 women, 25 men) suffering for normal pressure glaucoma. They had been referred to hospital for further follow up examination, if the diagnosis of glaucoma had already been made, or to explain defects in the visual field and abnormalities of the optic disc in those in whom glaucoma was suspected. Mean age was 58.0 (SD 13.9) years; the refractive error ranged from $-7 \cdot 25$ dioptres to +5 dioptres (mean $-0.21(2.26) \mathrm{D})$. The ametropia was on average $0.41(0.58)$ dioptres with a minimum of 0 dioptres and a maximum of 3.75 dioptres. Patients with a myopic refractive error exceeding -8 dioptres were excluded owing to a difference in optic disc morphology. ${ }^{10}$ Criteria for the diagnosis of normal pressure glaucoma were glaucomatous changes of the intrapapillary region of the optic nerve head such as an unusually small neuroretinal rim area in relation to the optic disc size, an abnormal shape of the neuroretinal rim, and cup to disc ratios being higher vertically than horizontally; localised or diffuse retinal nerve fibre layer defects; and glaucomatous visual field defects. The latter included a mean perimetric defect of more than $2 \mathrm{~dB}$ or a loss variance of more than $6 \mathrm{~dB}^{2}$ as evaluated repeatedly by the ocTOPUS G1 program on at 
least two test occasions. All patients showed bilateral visual field defects. The intraocular pressure had to be measured in at least two 24 hour pressure profiles with at least four measurements between $5 \mathrm{pm}$ and $7 \mathrm{am}$. It had to be less than $21 \mathrm{~mm} \mathrm{Hg}$. Neurological, neuroradiological, and general medical examination, including cranial computerised tomography scans, did not reveal any reason for optic nerve damage other than glaucoma.

For 76 eyes of 38 patients, 15 degree colour stereo optic disc transparencies had been taken using a telecentric fundus camera. For the remaining 36 patients a pair of 30 degree stereoscopical slides of the optic disc were available. These two subgroups did not differ significantly in sex, age, refractive error, and mean visual defect.

The disc slides were projected in a scale of 1 to 15 . The outlines of the optic cup, optic disc, peripapillary scleral ring, and parapapillary chorioretinal atrophy were plotted on paper and analysed morphometrically. To obtain values in absolute size units - that is, $\mathrm{mm}$ or $\mathrm{mm}^{2}$, the ocular and photographic magnifications were corrected according to Littmann's method taking into account the anterior corneal curvature and the refractive error. ${ }^{11}$ The 15 degree stereo photographs were evaluated in a masked fashion mixed together with the photographs of more than 500 patients with primary open angle glaucoma or other reasons for optic nerve damage. The 30 degree photographs were assessed in a separate group, firstly addressing all right eyes and then all left eyes without knowing which eye belonged to which person. The optic cup was defined on the basis of contour and not of pallor. The border of the optic disc was identical to the inner side of the peripapillary scleral ring. The latter was a thin white band encircling the optic disc. On the temporal disc side, it could be detected more easily than on the nasal side. The method has already been described in detail. ${ }^{12-14}$

For interindividual comparisons, only one randomly selected eye per patient was taken for statistical analysis. For the intraindividual bilateral comparison, the right eye of the patient was compared with his left eye.

\section{Results}

Mean optic disc area was 2.90 (SD 0.61$) \mathrm{mm}^{2}$ with a minimum of $1.69 \mathrm{~mm}^{2}$ and a maximum of $4.89 \mathrm{~mm}^{2}$. The side differences in disc area

Table 1 Optic disc area (SD) in different subgroups with increasing visual field defect

\begin{tabular}{lclll}
\hline & $n$ & $\begin{array}{l}\text { Visual field } \\
\text { defect }(\mathrm{dB})\end{array}$ & $\begin{array}{l}\text { Optic disc } \\
\text { area }\left(\mathrm{mm}^{2}\right)\end{array}$ & $\begin{array}{l}\text { Neuroretinal } \\
\text { rim area }\left(\mathrm{mm}^{2}\right)\end{array}$ \\
\hline Subgroup I & 30 & $\begin{array}{l}2.83(0.74) \\
(\mathrm{X} \leqslant 4 \mathrm{~dB})\end{array}$ & $3.07(0.63)$ & $1.17(0.38)$ \\
Subgroup II & 17 & $\begin{array}{l}5.25(0.88) \\
(4 \mathrm{~dB}<\mathrm{X} \leqslant 7 \mathrm{~dB})\end{array}$ & $2.99(0.66)$ & $0.94(0.31)$ \\
Subgroup III & 6 & $\begin{array}{l}8.37(1.02) \\
(7 \mathrm{~dB}<\mathrm{X} \leqslant 10 \mathrm{~dB})\end{array}$ & $2.57(0.50)$ & $0.82(0.43)$ \\
Subgroup IV & 7 & $\begin{array}{l}12.0(0.89) \\
(10 \mathrm{~dB}<\mathrm{X} \leqslant 13 \mathrm{~dB})\end{array}$ & $2.60(0.69)$ & $1.02(0.30)$ \\
Subgroup V & 6 & $\begin{array}{l}14.6(1.26) \\
(13 \mathrm{~dB}<\mathrm{X} \leqslant 17 \mathrm{~dB})\end{array}$ & $2 \cdot 80(0.38)$ & $0.57(0.23)$ \\
Subgroup VI & 8 & $\begin{array}{l}20.6(2.64) \\
(17 \mathrm{~dB}<\mathrm{X})\end{array}$ & $2 \cdot 70(0.47)$ & $0.44(0.20)$ \\
\hline
\end{tabular}

were on an average $0.26(0.26) \mathrm{mm}^{2}$ with a maximum of $1.08 \mathrm{~mm}^{2}$. Compared with the disc size, the mean relative side difference in optic disc area was $8 \cdot 9 \%(7 \cdot 3 \%)(0 \%$ to $47 \%)$.

Mean size of the neuroretinal rim area was $0.95(0.41) \mathrm{mm}^{2}$. Its side differences were an average $0.26(0.23) \mathrm{mm}^{2}$ (maximum 1.15 $\mathrm{mm}^{2}$ ) in absolute terms and $33.5 \%(38 \cdot 2 \%)$ $(0 \%$ to $204 \%)$ in relative terms.

Taking the study group as a whole, the optic disc area decreased significantly $(p=0.04)$ with increasing visual field defect (Fig 1 ). If the whole group was divided into subgroups according to increasing perimetric loss, the optic disc area decreased significantly $(p=0.03)$ from $3.07(0.63) \mathrm{mm}^{2}$ in the first subgroup to $2 \cdot 70(0.47) \mathrm{mm}^{2}$ in the subgroup with advanced nerve damage (Table 1). Accordingly, the difference in disc area between the first two subgroups with a mean perimetric loss of less than $7 \mathrm{~dB}$ and the four other subgroups with a mean visual field loss of equal to or more than $7 \mathrm{~dB}$ were significant $(p=0.02)$. Taking into account only the patients with a mean visual field loss of more than $7 \mathrm{~dB}$ (subgroups III-VI, Table 1), the disc area did not vary significantly between the patients with normal pressure glaucoma and 319 normal subjects (disc area $2.69(0.70)$ $\left.\mathrm{mm}^{2}\right)^{14}$ or 549 patients with primary open angle glaucoma (disc area $2.63(0.61) \mathrm{mm}^{2}$ ) who were evaluated in previous investigations. ${ }^{3}$

In the study group, the side differences in the optic disc area of the right eye-left eye were not correlated with the side differences in the mean visual field defect (Fig 2). It holds true also if the side differences in percentages were taken (Pearson's correlation coefficient $R=0 \cdot 16 ; \mathrm{p}=0 \cdot 17)$. To evaluate the statistical power of the negative result of the study, we determined the $95 \%$ confidence interval of the correlation coefficients. The correlation coefficient for the relation between the side differences in optic disc area on one hand and the mean visual field defect on the other hand was $R=0.08(\mathrm{p}=0.46)$. Taking into account the 74 cases, the $95 \%$ confidence interval for the correlation coefficients ranged from $R=-0 \cdot 18$ to $R=0 \cdot 25$. Assuming a correlation coefficient only of more than 0.30 to be clinically

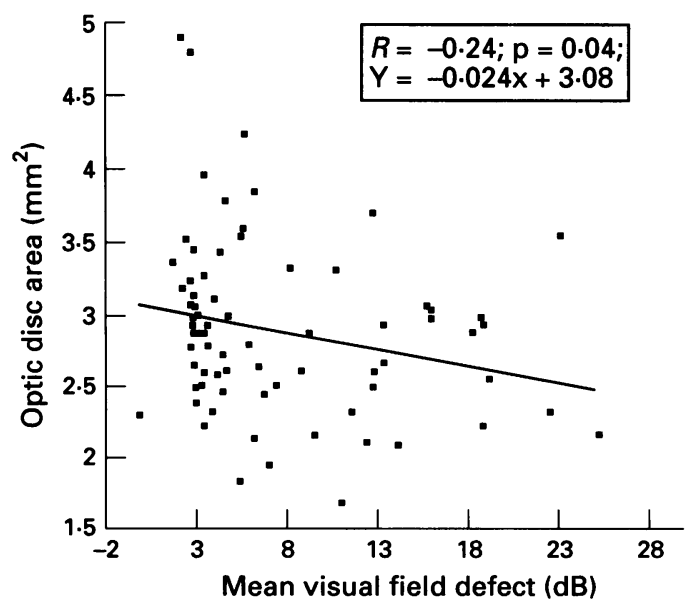

Figure 1 Scatterplot showing the correlation between mean visual field defect and optic disc area. 


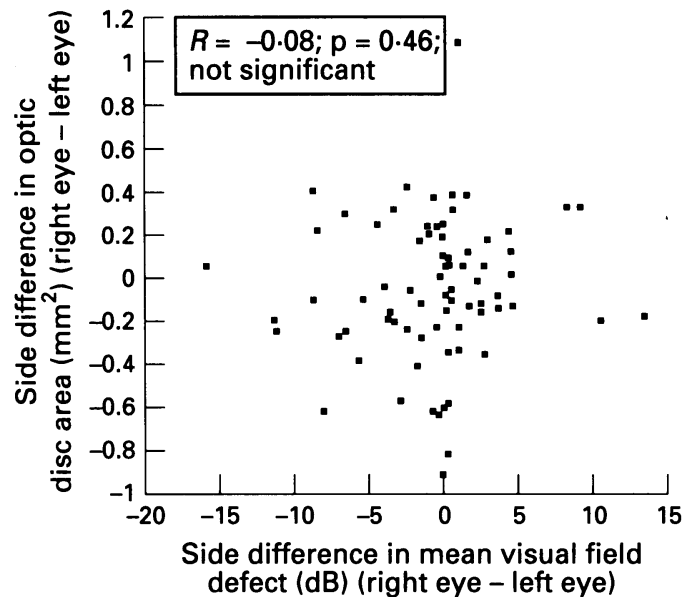

Figure 2 Scatterplot showing the correlation between the side differences in the optic disc area and the side difference in the mean visual field defect.

important, it indicates that even with a larger number of patients the relations between the side differences in optic disc area and the side differences in mean perimetric loss would not reach a clinically relevant level. Taking into account only those patients with an asymmetry in optic disc area of at least $0.1 \mathrm{~mm}^{2}, 0.2 \mathrm{~mm}^{2}$, $0.3 \mathrm{~mm}^{2}, 0.4 \mathrm{~mm}^{2}$, and $0.5 \mathrm{~mm}^{2}$, respectively, the correlation coefficients $R$ and the $\mathrm{p}$ values did not change much (Tables 2 and 3 ).

The side differences in the mean visual field defect were significantly correlated with the side differences in the area of the neuroretinal $\operatorname{rim}(R=-0.55 ; \mathrm{Y}=-0.04 \quad \mathrm{X}-0.04$; $\mathrm{p}<0.0001$ ).

\section{Discussion}

Several factors may affect the influence of the optic disc size on the susceptibility for glaucomatous optic nerve fibre loss. Non-arteritic anterior ischaemic optic neuropathy and optic disc drusen occur more frequently in small optic nerve heads than in large optic discs. ${ }^{15-18}$ For both entities, similar pathogenetic mechanisms have been discussed as for glaucoma that is, a perfusion problem as for the ischaemic optic neuropathy, and a blockage of the orthograde axoplasmic flow as in the case of optic disc drusen. In the optic disc, the optic nerve fibres are more crowded in eyes with small optic nerve heads than in eyes with large discs. ${ }^{19}$ A dense arrangement of the nerve fibres in small optic discs may suggest that the lamina cribrosa mechanically deformed by the glaucomatous process may more easily press the optic nerve fibres in small optic discs than in large optic nerve heads. Eyes with small optic discs have been reported to possess a slightly smaller number of optic nerve fibres than eyes with large optic nerve heads. ${ }^{19} 20$ This suggests that eyes with small optic discs have a smaller anatomical reserve capacity. Other studies have suggested that the higher glaucoma susceptibility in the inferior and superior disc regions, compared with the temporal and nasal disc sectors, ${ }^{21}$ is associated with a higher percentage of pore area to disc area. $^{22} 23$ This ratio increases with decreasing optic disc size. ${ }^{24}$ All these factors would
Table 2 Pearson's correlation coefficients $\mathrm{R}$ and $p$ values for the correlations between the side differences in optic disc area and the side differences in mean visual field defect expressed in absolute terms

\begin{tabular}{llll}
\hline $\begin{array}{l}\text { Side difference } \\
\text { in optic disc area }\left(\mathrm{mm}^{2}\right)\end{array}$ & $n$ & $\begin{array}{l}\text { Correlation } \\
\text { coefficient }\end{array}$ & $p$ Value \\
\hline$>0.1$ & 58 & 0.10 & 0.46 \\
$>0.2$ & 40 & 0.11 & 0.52 \\
$>0.3$ & 24 & 0.14 & 0.52 \\
$>0.4$ & 11 & 0.15 & 0.67 \\
$>0.5$ & 9 & 0.24 & 0.55 \\
\hline
\end{tabular}

Table 3 Pearson's correlation coefficients $\mathrm{R}$ and $p$ values for the correlations between the side differences in optic disc area and the side differences in mean visual field defect expressed in relative terms (side difference in disc area divided by disc area correlated with the side difference in mean visual field defect divided by the perimetric sensitivity)

\begin{tabular}{llll}
\hline $\begin{array}{l}\text { Side difference } \\
\text { in optic disc area }\left(\mathrm{mm}^{2}\right)\end{array}$ & $n$ & $\begin{array}{l}\text { Correlation } \\
\text { coefficient }\end{array}$ & $p$ Value \\
\hline$>0 \cdot 1$ & 58 & $0 \cdot 18$ & $0 \cdot 17$ \\
$>0.2$ & 40 & $0 \cdot 19$ & $0 \cdot 25$ \\
$>0.3$ & 24 & $0 \cdot 17$ & 0.44 \\
$>0.4$ & 11 & $0 \cdot 17$ & 0.61 \\
$>0.5$ & 9 & $0 \cdot 17$ & 0.66 \\
\hline
\end{tabular}

predispose eyes with small optic discs to glaucomatous optic nerve damage.

On the other hand, deducing from purely mechanical factors, the pressure gradient across the lamina cribrosa produces a more pronounced displacement of the lamina cribrosa in large optic discs than in small optic nerve heads. ${ }^{1}$ Inside the optic disc, the susceptibility for neuroretinal rim loss is higher in regions with a long distance to the central retinal vessel trunk than in sectors with a short distance. ${ }^{25}$ These factors mean a higher risk for glaucomatous damage in eyes with large discs. Summarising all these factors, one might infer that their effects might compensate each other. This hypothesis is strengthened by the results of the present study. In the intraindividual bilateral comparison, the eye with the larger optic disc, when compared with the contralateral eye with the smaller optic nerve head, neither showed more marked nor less pronounced glaucomatous optic nerve damage. A similar result was obtained in another study on patients with primary open angle glaucoma. ${ }^{26}$ The results of both studies indicate that for a given patient the degree of the glaucomatous optic nerve atrophy was not markedly associated with the optic disc size. The finding in the present study that eyes with large visual field defects, compared with eyes with moderate perimetric loss, had a smaller optic disc may indicate that the unusually large optic disc size in eyes with normal pressure glaucoma as found in several cross sectional studies may at least partially be due to selection.

In spite of the statistical significance or nonsignificance of the findings, there are factors limiting the present study. The bias in the selection of patients referred to a hospital may be present in our study as well as in the preceding investigations. ${ }^{2-4} \mathrm{~A}$ lack of intraindividual correlation between field loss and disc size is not absolutely indicative of interindividual susceptibility to glaucoma with disc size. Furthermore, the asymmetry in disc size was not very marked so that findings might have escaped from 
statistical significance solely because of the small difference between the two eyes and a relatively small number of patients involved. If, however, only those patients with an asymmetry of larger than $0.2 \mathrm{~mm}^{2}$ or $0.5 \mathrm{~mm}^{2}$ were taken into account, the relation between the asymmetry in disc size and the asymmetry in field defect did not show a tendency towards a statistically significant result (Table 2). The same holds true if the side differences were expressed in percentages (Table 3 ). In conclusion, however, only a carefully controlled large scale epidemiologically based study will finally be able to answer the question whether a large optic disc size predisposes to glaucomatous optic nerve fibre loss.

Presented in part at the annual meeting of the Association for Research in Vision and Ophthalmology, held at Sarasota, 1 May to 6 May 1994.

to 6 May 1994 . Supported by the Deutsche Forschungsgemeinscha
(Klinische Forschergruppe 'Glaukome', DFG Na 55/6-2).

1 Chi T, Ritch R, Strickler D, Pitman B, Tsai C, Hsieh FY. Racial differences in optic nerve head parameters. Arch Ophthalmol 1989; 107: 836-9.

2 Tuulonen A, Airaksinen PJ. Optic disc size in exfoliative, primary open-angle, and low-tension glaucoma. Arch Ophthalmol 1992; 110: 211-3.

3 Jonas JB. Size of glaucomatous optic discs. German $\mathfrak{f}$ Ophthalmol 1992; 1: 41-4.

4 Burk ROW, Rohrschneider K, Noac H, Völcker HE. Are large optic nerve heads susceptible to glaucomatous large optic nerve heads susceptible to glaucomatous damage at normal intraocular pressure.

5 Bengtsson $B$. The variation and covariation of cup and disc diameters. Arch Ophthalmol 1976; 54: 804-18.

6 Betz Ph, Camps Fr, Collignon-Brach C, Weekers R. Photographie stéréoscopique et photogrammétrie de l'excavation physiologique de la papille. f Fr Ophtalmol 1981; 4: 193-203.

7 Caprioli J, Miller JM. Optic disc rim area is related to disc size in normal subjects. Arch Ophthalmol 1987; 105:

8 Jonas JB, Fernández MC, Naumann GOH. Glaucomatous optic nerve damage in small discs with low cup-to-disk ratios. Ophthalmology 1990; 97: 1211-5

9 Jonas JB, Xu L. Parapapillary chorioretinal atrophy in normalpressure glaucoma. Am $\mathcal{f}$ Ophthalmol 1993; 115: 501-5.
10 Jones JB, Gusek GCh, Naumann GOH. Optic disk morphometry in high myopia. Graefes Arch Clin Exp Ophthalmol 1988; 226: 587-90.

11 Littmann H. Zur Bestimmung der wahren Größe eines Objektes auf dem Hintergrund des lebenden Auges. Klin Monatsbl Augenheilkd 1982; 180: 286-9.

12 Drance SM, Balazsi G. Die neuroretinale Randzone beim frühen Glaukom. Klin Monatsbl Augenheilkd 1984; 184: 271-3.

13 Airaksinen PJ, Drance SM, Schulzer M. Neuroretinal rim area in early glaucoma. Am $f$ Ophthalmol 1985; 99: $1-4$.

14 Jonas JB, Gusek GC, Naumann GOH. Optic disc, cup and neuroretinal rim size, configuration, and correlations in normal eyes. Invest Ophthalmol Vis Sci 1992; 33: tions in 5 .

15 Beck RW, Savino PJ, Repka MX, Schatz NJ, Sergott RC. Optic disc structure in anterior ischemic optic neuropathy. Ophthalmology 1984; 91: 1334-7.

16 Jonas JB, Gusek GC, Naumann GOH. Anterior ischemic optic neuropathy: nonarteritic form in small and giant cell arteritis in normal sized optic discs. Int Ophthalmol 1988; 12: 119-25.

17 Spencer WH. Drusen of the optic disk and aberrant axoplasmac transport. The XXXIV Edward Jackson Memorial Lecture. Am $f$ Ophthalmol 1978; 85: 1-12.

18 Jonas JB, Gusek GCh, Guggenmoos-Holzmann I, Naumann GOH. Optic nerve head drusen associated with abnormally small optic discs. Int Ophthalmol 1987; 11: 79-82.

19 Jonas JB, Schmidt AM, Müller-Bergh JA, SchlötzerSchrehardt UM, Naumann GOH. Human optic nerve fiber count and optic disc size. Invest Ophthalmol Vis Sci 1992; 33: 2012-8.

20 Quigley HA, Coleman AL, Dorman-Pease ME. Larger optic nerve heads have more nerve fibers in norma monkey eyes. Arch Ophthalmol 1991; 109: 1441-3.

21 Quigley HA, Addicks EM, Green WR, Maumenee AE. Optic nerve damage in human glaucoma. II. The site of injury and susceptibility to damage. Arch Ophthalmol injury and susceptib

22 Radius RL. Regional specificity in anatomy at the lamina cribrosa. Arch Ophthalmol 1981; 99: 478-80.

23 Quigley HA, Addicks EM. Regional differences in the structure of the lamina cribrosa and their relation to glaucomatous optic nerve damage. Arch Ophthalmol 1981; 99: 137-43.

24 Jonas JB, Mardin CY, Schlötzer-Schrehardt U, Naumann GOH. Histomorphometry of the human lamina cribrosa surface. Invest Ophthalmol Vis Sci 1991; 32: 401-5.

25 Jonas JB, Fernández $M$. Shape of the neuroretinal rim and the position of the central retinal vessels in glaucoma. $\mathrm{Br} \mathcal{F}$ Ophthalmol 1994; 78: 99-102.

26 Jonas JB, Fernández MC, Naumann GOH. Correlation of the optic disc size to glaucoma susceptibility. Ophthalmology 1991; 98: 675-80. 